\title{
Protons Trap NR1/NR2B NMDA Receptors in a Nonconducting State
}

\author{
Tue G. Banke, Shashank M. Dravid, and Stephen F. Traynelis \\ Department of Pharmacology, Emory University School of Medicine, Atlanta, Georgia 30322
}

\begin{abstract}
NMDA receptors are highly expressed in the CNS and are involved in excitatory synaptic transmission, as well as synaptic plasticity. Given that overstimulation of NMDA receptors can cause cell death, it is not surprising that these channels are under tight control by a series of inhibitory extracellular ions, including zinc, magnesium, and $\mathrm{H}^{+}$. We studied the inhibition by extracellular protons of recombinant NMDA receptor NR1/NR2B single-channel and macroscopic responses in transiently transfected human embryonic kidney HEK 293 cells using patch-clamp techniques. We report that proton inhibition proceeds identically in the absence or presence of agonist, which rules out the possibility that protonation inhibits receptors by altering coagonist binding. The response of macroscopic currents in excised patches to rapid jumps in $\mathrm{pH}$ was used to estimate the microscopic association and dissociation rates for protons, which were $1.4 \times 10^{9}$ $\mathrm{M}^{-1} \mathrm{sec}^{-1}$ and $110-196 \mathrm{sec}^{-1}$, respectively $\left(K_{\mathrm{d}}\right.$ corresponds to $\mathrm{pH}$ 7.2). Protons reduce the open probability without altering the time course of desensitization or deactivation. Protons appear to slow at least one time constant describing the intra-activation shut-time histogram and modestly reduce channel open time, which we interpret to reflect a reduction in the overall channel activation rate and possible proton-induced termination of openings. This is consistent with a modest proton-dependent slowing of the macroscopic response rise time. From these data, we propose a physical model of proton inhibition that can describe macroscopic and single-channel properties of NMDA receptor function over a range of $\mathrm{pH}$ values.
\end{abstract}

Key words: NMDA receptor; protons; ion channel; ischemia; $\mathrm{pH}$; glutamate

\section{Introduction}

The most abundant excitatory amino acid in the vertebrate CNS is L-glutamate. Glutamate is involved in normal as well as pathological brain function and plays a key role in fast synaptic transmission. Glutamate binds to ionotropic glutamate receptors (GluRs), which can be divided into three classes according to their pharmacology, molecular structure, and biophysical properties: AMPA, kainate, and NMDA receptors (McBain and Mayer, 1994; Dingledine et al., 1999; Erreger et al., 2004). Overstimulation of NMDA receptors by the extracellular glutamate that accumulates under ischemic conditions (such as during stroke) can lead to cytotoxic levels of $\mathrm{Ca}^{2+}$ and other divalent ions within neurons. In addition, overactivation of NMDA receptors has been suggested to participate in the initiation and maintenance of seizures. Together, the involvement of glutamate receptors in these conditions makes this receptor class a potential therapeutic target for treatment of stroke and epilepsy (Kohl and Dannhardt, 2001; Danysz and Parsons, 2002; Kemp and McKer-

Received Aug. 2, 2004; revised Nov. 13, 2004; accepted Nov. 14, 2004

This work was supported by the Alfred Benzon Foundation (T.G.B.), by the Danish Medical Research Council (T.G.B.), and by National Institutes of Health Grant NS36654 (S.F.T.). We thank D. Colquhoun for sharing software. We also thank J. Lee for writing software for converting AXON files into readable SCAN files. We thank T. Auerbach and K. Erreger for critical comments on this manuscript. We are also grateful to Chris McBain for support during completion of modeling and writing of this manuscript.

Correspondence should be addressed to Tue Banke at his present address: Laboratory of Cellular and Synaptic Neurophysiology, National Institutes of Health, Porter Neuroscience Research Center, Building 35, Room 3C-705, 35 Lincoln Drive, Bethesda, MD 20892. E-mail: banket@mail.nih.gov.

D0I:10.1523/JNEUROSCI.3154-04.2005

Copyright $\odot 2005$ Society for Neuroscience $\quad 0270-6474 / 05 / 250042-10 \$ 15.00 / 0$ nan 2002). Perhaps to offset these potentially harmful actions of NMDA receptor overactivation, these channels are under tight negative regulation by the endogenous extracellular ions $\mathrm{Zn}^{2+}$ and $\mathrm{Mg}^{2+}$, as well as physiological concentrations of $\mathrm{H}^{+}$.

NMDA receptors expressed by forebrain and cerebellar neurons are inhibited by protons with an $\mathrm{IC}_{50}$ value in the range of pH 6.9-7.3 [50-126 nм H ${ }^{+}$(Giffard et al., 1990; Tang et al., 1990; Traynelis and Cull-Candy, 1990; 1991; Vyklicky et al., 1990)]. Interstitial pH undergoes multiphasic changes during normal synaptic transmission and much larger changes during seizure activity and ischemia, during which $\mathrm{pH}$ levels can fall by 0.2-0.6 pH units (Siesjo, 1985; Balestrino and Somjen, 1988; Nedergaard et al., 1991; Chesler and Kaila, 1992). Because neuronal injury during both seizure and ischemia is associated with glutamate release (Hirano et al., 2003) and NMDA receptor activation, mild acidification of the extracellular space in the penumbra might be expected to limit the extent of glutamate-induced neurotoxicity, although acidification in the infarct core can be harmful. In support of this hypothesis, decreasing extracellular $\mathrm{pH}$ to a level observed during ischemia reduces the contribution of NMDA receptors to neuronal death in cortical cultures (Giffard et al., 1990; Kaku et al., 1993) and can increase seizure threshold in vivo (Balestrino and Somjen, 1988).

Allosteric regulators such as polyamines acting at NR1/NR2B NMDA receptors (Traynelis et al., 1995), ifenprodil acting at NR1/NR2B (Mott et al., 1998), and zinc acting at NR1/NR2A (Choi and Lipton, 1999; Low et al., 2000; Paoletti et al., 2000, Traynelis et al., 1998) have been proposed to exert their actions 
through modification of tonic inhibition by physiological $\mathrm{pH}$. Thus, proton-sensitive gating could be a downstream feature of receptor activation that is regulated by exogenous molecules and therapeutic agents. In this report, we explore the effects of protons on channel activation. All of our results support the working hypothesis that protonation of key residue(s) increases the proportion of receptors that enter a nonconducting mode that retains the ability to bind coagonists and desensitize with rates similar to unprotonated receptors.

\section{Materials and Methods}

Tissue culture. Human embryonic kidney (HEK) 293 cells were maintained as described previously (Banke and Traynelis, 2003) and plated onto $12 \mathrm{~mm}$ glass coverslips that were coated with poly-D-lysine (5-10 $\mu \mathrm{g} / \mathrm{ml})$. cDNAs encoding NR1-1a (hereafter NR1; GenBank accession number U08621) and NR2B (GenBank accession number U11419) in pcIneo and pcDNA1/amp, respectively (provided by Dr. S. Heinemann, Salk Institute, CA), were transiently transfected into cells using the Caphosphate precipitation method (Chen and Okayama, 1987). The ratio of cDNAs encoding NR1/NR2/GFP for experiments with one channel patch was 1:2:12, with a final NR1 cDNA concentration of $0.08 \mu \mathrm{g} / \mathrm{ml}$. To obtain larger macroscopic currents, we used a transfection ratio of 1:1:1.5 for NR1/NR2B/GFP and a final concentration of $0.5 \mu \mathrm{g} / \mathrm{ml} \mathrm{NR} 1 \mathrm{cDNA}$. Cells remained in the transfection solutions for $2-5 \mathrm{hr}$ for single-channel patch experiments and $6-8 \mathrm{hr}$ for macroscopic experiments, after which the media was replaced and supplemented with $2-3 \mathrm{mM} \mathrm{Mg}^{2+}$ and 200 $\mu \mathrm{M}$ APV.

Electrophysiology. Recordings were typically made over $24 \mathrm{hr}$ after transfection. Glutamate was applied using a piezoelectric translator (Burleigh Instruments, Fishers, NY) to move a double-barreled flow pipe constructed from theta tubing (Hilgenberg, Malsfeld, Germany) or a triple barrel square flow pipe (product \#3SG700-5; Warner Instruments, Hamden, CT). At the end of recording, the patch was destroyed, and open-tip junction potentials were used to determine the duration and time course of agonist application; junction potentials typically had $10-90$ rise times of $0.3-0.7 \mathrm{msec}$. External recording solution for all experiments was composed of the following (in $\mathrm{mM}$ ): $150 \mathrm{NaCl}, 10$ HEPES, $3 \mathrm{KCl}, 0.7 \mathrm{CaCl}_{2}$, and 0.2 EDTA, pH $7.4(\mathrm{NaOH})(310-330$ mOsm, $\left.23^{\circ} \mathrm{C}\right)$. The reduction of free extracellular $\mathrm{Ca}^{2+}$ to $0.5 \mathrm{~mm}$ reduced the frequency of subconductance levels (Premkumar et al., 1997; Banke and Traynelis, 2003); EDTA was added to remove contaminant divalent cations. All experiments were performed at $23^{\circ} \mathrm{C}$. The internal solution was composed of the following (in $\mathrm{mM}$ ): 110 gluconic acid, 30 $\mathrm{CsCl}, 4 \mathrm{NaCl}, 5 \mathrm{HEPES}, 5 \mathrm{BAPTA}, 0.5 \mathrm{CaCl}_{2}$, and $2 \mathrm{MgCl}_{2}, \mathrm{pH}$ 7.3 $(\mathrm{CsOH})(290-300 \mathrm{mOsm})$. All solutions contained a maximal concentration of glycine $\left(20 \mu \mathrm{M}\right.$ or $\left.\sim 50 \times \mathrm{EC}_{50}\right)$ unless stated otherwise. For single-channel recording, thick-walled borosilicate glass $(1.5 \mathrm{~mm}$ outer diameter; $0.85 \mathrm{~mm}$ inner diameter; Warner Instruments) was fire polished to a resistance of 6-9 M , and Sylgard (Dow Corning, Midland, MI) was applied to the pipette tip.

Data analysis. Single-channel and macroscopic data were digitized at 13-40 kHz using Clampex version 8.0 (Axon Instruments, Union City, $\mathrm{CA}$ ) after filtering at $5 \mathrm{kHz}$ (eight-pole Bessel, $-3 \mathrm{~dB}$; Frequency Devices, Haverhill, MA). Data for some experiments were first stored on DAT tape (Sony, Tokyo, Japan) at $48 \mathrm{kHz}$. Single-channel records were analyzed using the Viterbi algorithm in QUB Software (www.qub.buffalo.edu) and time course fitting in SCAN (provided by Dr. Colquhoun, University College London, UK; http://www.ucl.ac.uk/pharmacology/ dcpr95.html); both analyses gave identical results. Open- and closedduration histograms were fitted with multiple-exponential components in ChanneLab using maximum likelihood method (Colquhoun and Sigworth, 1995). For single-channel patches stimulated with a brief pulse of glutamate, fitting of the sequence of open and closed durations was performed (first to last open time) on records pooled from five to six experiments, with initial occupancy set to be in the open state. For singlechannel patches in the continuous presence of glutamate, fitting of the sequence of open and closed durations was performed (first to last open time) on records pooled from four to eight patches. $T_{\text {crit }}$ was used to identify individual receptor activations and was defined as being longer than the fifth shut-time distribution component $(>2 \mathrm{sec})$; all shut times longer than $2 \mathrm{sec}$ were omitted. Fitting of macroscopic response time course was performed with ChanneLab (Synaptosoft, Decatur, GA) or Clampfit (Axon Instruments). Deconvolution analysis was performed in custom software (NPM, written by S.F.T.) by first creating an impulse response function and filtering at $0.6 \mathrm{kHz}(\tau$ of $0.4 \mathrm{msec})$. The data were deconvolved with this filtered impulse function to determine the effect of the solution exchange on the response time course during changes in proton concentration. Relaxations with $\tau$ values of 2, 6, or 10 msec were, respectively, slowed by 30,22 , and $12 \%$; appropriate corrections were applied to the data in Figure 4. For each patch, an average file was made from 5-10 sweeps, and the rising phase was analyzed. Proton concentration was calculated using an activity coefficient of 0.8 .

\section{Results \\ Activation, deactivation, and desensitization of NMDA receptors}

Extracellular protons inhibit neuronal NMDA receptors (Traynelis and Cull-Candy, 1990, 1991; Tang et al., 1990; Vyklicky et al., 1990; Yoneda et al., 1994) with an $\mathrm{IC}_{50}$ value in the physiological $\mathrm{pH}$ range; inhibition is complete at high concentrations (e.g., $1 \mu \mathrm{M}$ ) of protons. To explore the mechanism of proton inhibition, we studied recombinant NR1/NR2B receptors in excised membrane patches. To evaluate the effects of proton inhibition of NMDA receptors on the time course of the macroscopic response, outside-out patches containing multiple channels were pulled from HEK 293 cells expressing rat NR1/NR2B receptors and stimulated with a brief synaptic-like (1-4 msec) pulse of $1 \mathrm{~mm}$ glutamate at three different $\mathrm{pH}$ values $(6.9,7.4$, and 7.9); saturating glycine $(20 \mu \mathrm{M})$ was always present unless stated otherwise. The time course of the deactivation could best be described by a dual-exponential function (Fig. 1A), with time constants for $\tau_{\text {FAST }}$ between 93 and 102 msec and for $\tau_{\text {SLOW }}$ between 569 and 595 msec over three different $\mathrm{pH}$ values ( $\mathrm{pH} 6.9,7.4$, and 7.9) (Fig. $1 B$ ). Neither the time constants describing deactivation nor the relative amplitudes of each component were significantly different at any of the $\mathrm{pH}$ values tested. These data suggest that the decay time course for NMDA receptor-mediated EPSCs will be $\mathrm{pH}$ insensitive.

We additionally evaluated whether the onset or recovery from desensitization was sensitive to extracellular $\mathrm{pH}$. To measure the onset of desensitization, we analyzed the decay time course of NMDA receptor responses in outside-out patches during stimulation with a long $(3 \mathrm{sec}$ ) pulse of $1 \mathrm{~mm}$ glutamate at three different $\mathrm{pH}$ values. The decay time course could be best fit by a dualexponential function with $\tau_{\text {FAST }}$ between 95 and $129 \mathrm{msec}$ and $\tau_{\text {SLOW }}$ between 549 and $711 \mathrm{msec}$ (Fig. 1C). No significant differences in the desensitization time course were found for any of the conditions tested. As shown previously by Lester and Jahr (1992), even a brief pulse of glutamate can induce some degree of desensitization (Fig. 1D). We therefore monitored recovery from this state using a double-pulse paradigm, as shown in Figure $1 D$. Similar time constants described recovery from desensitization when patches were challenged by a brief pulse of high concentration of glutamate at $\mathrm{pH} 6.9,7.4$, or 7.9 (Fig. $1 D$ ). These data suggest that protons do not mediate their inhibitory actions through alterations in the onset or recovery from desensitization.

We proposed previously that NMDA receptor activation requires two conformational changes that precede pore dilation and that these changes also influence the rise time of the response (Banke and Traynelis, 2003). We therefore measured the rate of rise as a function of $\mathrm{pH}$. Multiple responses to a brief pulse of a maximal concentration of glutamate applied to the patch at dif- 
ferent $\mathrm{pH}$ values were averaged, and the $10-90 \%$ rise time was determined (Fig. $2 A, B)$. The rise time was significantly slowed at $\mathrm{pH} 6.9-150 \pm 9 \%(n=8 ; p=$ 0.02 ; paired $t$ test) of that observed at $\mathrm{pH}$ 7.4 ; rise times were not significantly different at $\mathrm{pH} 7.9$ versus $\mathrm{pH}$ 7.4. We subsequently fitted the rising phase to an exponential function to obtain an estimate of the macroscopic activation rate. The mean time constant describing the rising phase of responses recorded at $\mathrm{pH} 6.9$ was significantly slower than those determined at pH 7.4 and 7.9 ( $p<0.018$; ANOVA; Tukey's test). Activation rates, calculated as the reciprocal of the time constant, were $130 \mathrm{sec}^{-1}$ at $\mathrm{pH} 7.9$ and $59 \mathrm{sec}^{-1}$ at $\mathrm{pH} 6.9$. Consistent with these data, the mean first latency determined in patches that contained only a single active channel (see below) was also significantly lengthened from $25.0 \pm 5.5 \mathrm{msec}$ at $\mathrm{pH} 7.9(n=305$ activations) to $35.4 \pm 2.9 \mathrm{msec}$ at $\mathrm{pH} 6.9$ $(n=370 ; p<0.04 ; t$ test) (Fig. $2 C)$.

\section{Protonation does not block glutamate and glycine binding}

Previous reports suggest that protons do not shift the $\mathrm{EC}_{50}$ value for glutamate activation of NMDA receptors; a modest shift (less than twofold) in the glycine $\mathrm{EC}_{50}$ reported previously is insufficient to account for the inhibitory actions of protons (Tang et al., 1990; Traynelis and Cull-Candy, 1990,1991). These data suggest that protonation of the NMDA receptor is unlikely to alter microscopic binding rates for glutamate and has only minor effects on glycine binding. However, these experiments cannot rule out the possibility that protons titrate receptors such that they simply do not bind either coagonist once protonated. To directly test whether proton inhibition involves inactivation of either glutamate or glycine binding sites, we recorded from HEK 293 cells expressing NR1/NR2B receptors in the whole-cell configuration while rapidly changing the solution from one with saturating concentration of glutamate $(100 \mu \mathrm{M})$ plus glycine $(20 \mu \mathrm{M})$ into solutions with only glycine. In doing this, we found that alkaline shift in $\mathrm{pH}$ still produced a rapid increase in current even in the absence of glutamate, suggesting that recovery from proton inhibition does not involve glutamate binding. Likewise, acidification after glutamate removal rapidly inhibits the receptor in the absence of glutamate, suggesting that proton inhibition does not reflect blockade of glutamate binding (Fig. 3A). The reverse experiment, jumping from solution with glycine plus glutamate into a solution with only glutamate (Fig. $3 B$ ), gave quantitatively similar results. Figure $3 C$ shows a whole-cell recording in which glutamate and glycine are both present at $\mathrm{pH} 7.9$, and the extracellular $\mathrm{pH}$ is altered in the continuous presence of these coagonists. The NMDA receptor concentration-response curve for $\mathrm{pH}$ inhibition was identical under all three conditions (Fig. $3 E$ ), with an $\mathrm{IC}_{50}$ corresponding to $\mathrm{pH} 7.1$ in the presence of both coagonists and $\mathrm{pH} 6.9-7.1$ in the presence of either coagonist. These data suggest that proton inhibition does not reflect a blockade of either glutamate or glycine binding. These experiments are also
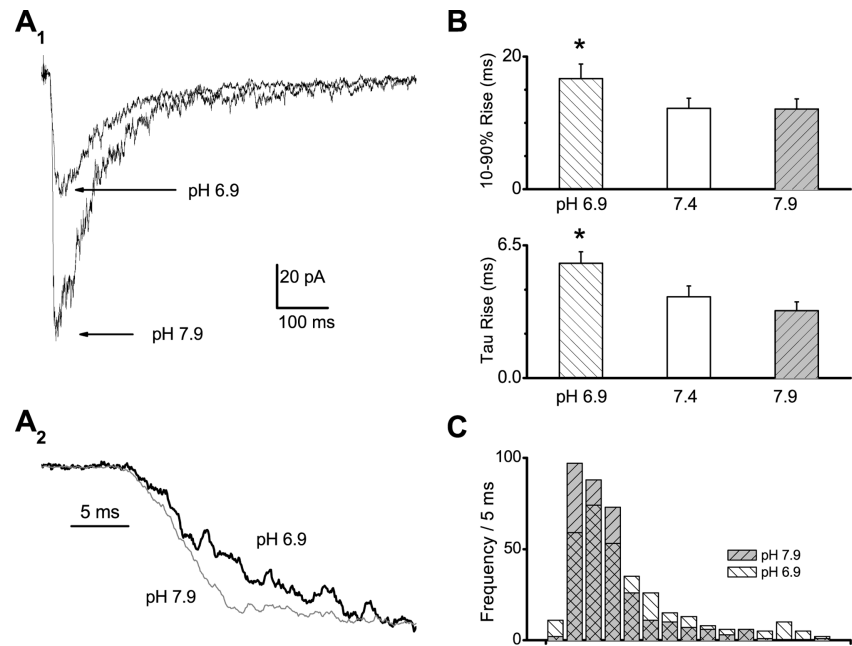

C

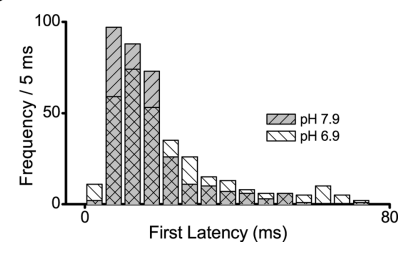

Figure 2. NR1/NR2B response rise time is $p H$ dependent. $A$, The average NR1/NR2B response from a patch that was stimulated with a 1-4 msec pulse of $1 \mathrm{~mm}$ glutamate at $\mathrm{pH} 6.9$ and 7.9 . The rising phase of the average of responses is shown on an expanded scale below. $B$, The average rise time significantly varied as a function of $\mathrm{pH}$ ( $p<0.02$; paired $t$ test between $\mathrm{pH} 7.4$ and 6.9). Five to 10 sweeps were averaged from each of six to eight patches. The average time constant describing an exponential equation fitted to the rising phase was also significantly slowed at pH 6.9 compared with pH 7.4 and 7.9 (ANOVA; Tukey's test; $p<0.018$ ). C, The first-latency histogram from patches that contained a single active channel revealed that the slowing of the rise time at $\mathrm{pH} 6.9$ in part reflects a delay in channel opening. 
A Glutamate
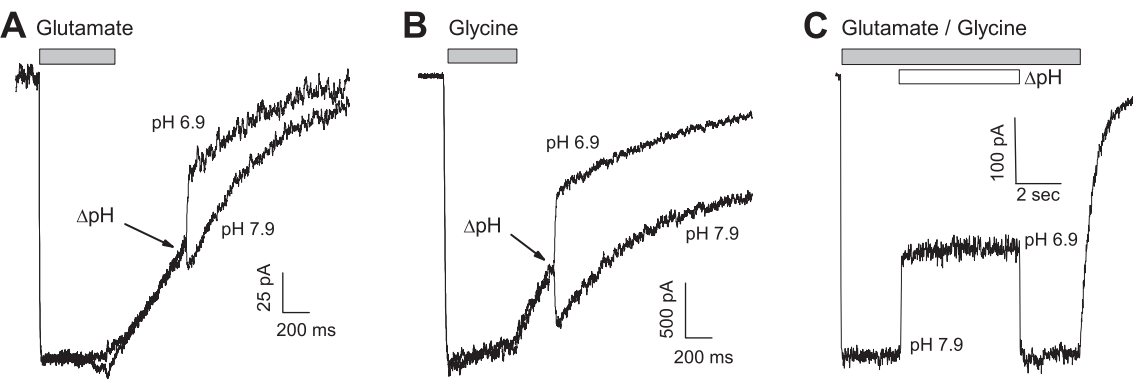

D
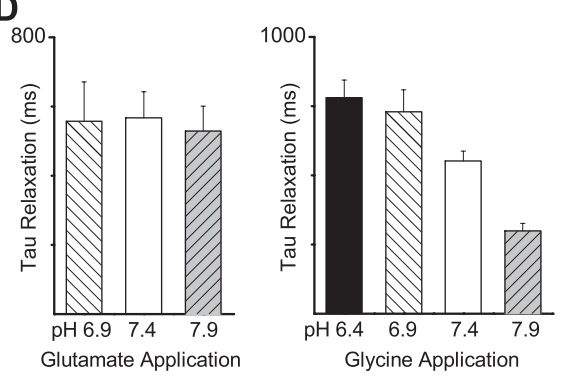

E

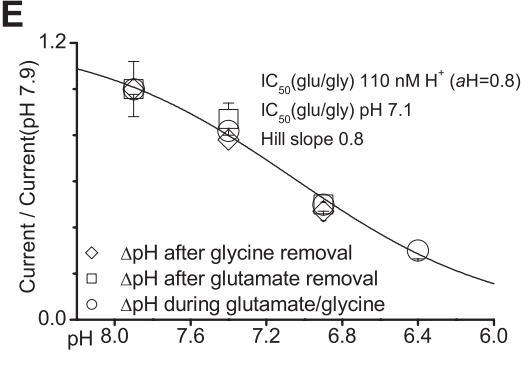

Figure 3. Proton inhibition of NR1/NR2B does not reflect block of ligand binding. $A$, Whole-cell current responses of HEK 293 cells expressing NR1/NR2B are shown in response to application of $100 \mu \mathrm{m}$ glutamate (bar); $20 \mu \mathrm{m}$ glycine was present in all solutions. During the current relaxation after glutamate removal, the extracellular solution was rapidly switched to one of identical composition, except that $\mathrm{pH}$ was either 7.9 or 6.9. A rapid increase or decrease in current amplitude was observed when $\mathrm{pH}$ was changed to $\mathrm{pH} 7.9$ or 6.9 , respectively. $B$, Similar results were obtained when cells were bathed in the continuous presence of $100 \mu \mathrm{m}$ glutamate and NR1/NR2B responses were stimulated by application of $20 \mu \mathrm{m}$ glycine. During the current relaxation after glycine removal, fast solution exchange was performed into $\mathrm{pH} 7.9$ and 6.9.C, The NR1/NR2B whole-cell current response is shown for changes in extracellular $\mathrm{pH}$ during coapplication of glutamate and glycine. For all experiments, holding potential was $-60 \mathrm{mV}$. D, The decay phase after $\Delta \mathrm{pH}$ from traces shown in $A$ and $B$ were fitted by a singleexponential function. Mean $\tau$ values are shown. $E$, Composite concentration-response curves are shown for the effects of $\mathrm{pH}$ on current amplitude for each of the three different experimental protocols. $\mathrm{IC}_{50}$ values ranged between $\mathrm{pH} 6.9$ and 7.1 ; the Hill slope ranged between 0.8 and 1.0 .
A

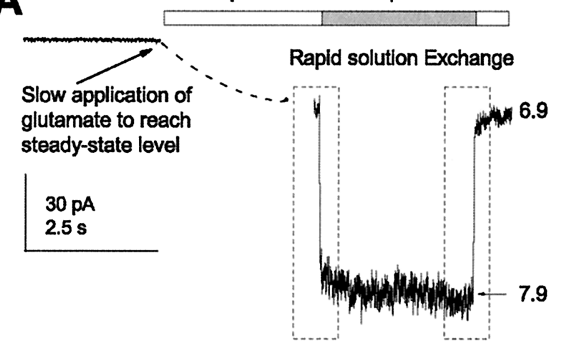

B

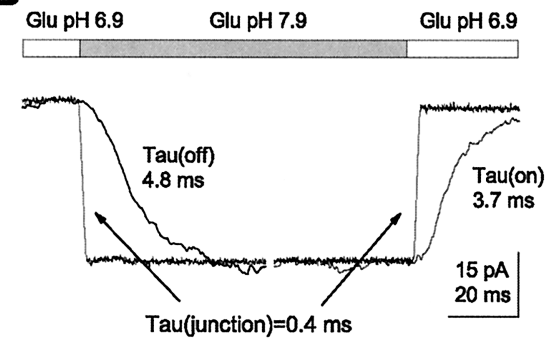

C
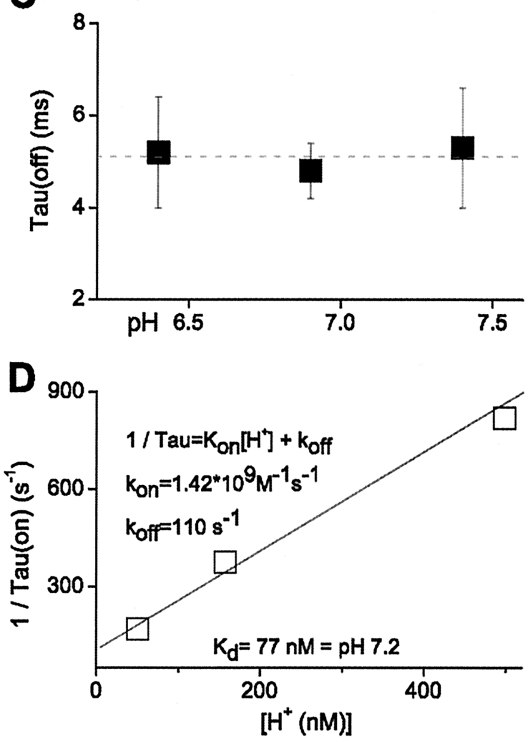

Figure 4. Proton binding to NR1/NR2B is fast. $A, B$, Macroscopic current response in outside-out patches that were slowly lifted into the solution stream (1 mm glutamate and $20 \mu \mathrm{m}$ glycine, $\mathrm{pH} 6.9$ ) and then rapidly moved into solution with different $\mathrm{pH}$. The rising and falling phase of the current response after rapid $\mathrm{pH}$ jumps were each fitted to a monoexponential function. $\tau_{\text {on }}$ and $\tau_{\text {off }}$ for solution exchange junction potential determined after each experiment were on average $0.4 \mathrm{msec} . C, \tau_{\text {off }}$ is independent of pH. $D$, The reciprocal of the mean $\tau_{\text {on }}$ is plotted as a function of proton concentration (calculated using an activity coefficient of 0.8 ). The data were fitted with the following linear equation: $1 / \tau_{\text {on }}=k_{\text {on }}\left[\mathrm{H}^{+}\right]+k_{\text {off. }}$. Fitted values for $k_{\text {on }}$ and $k_{\text {off }}$ were $1.42 \times 10^{9}$ $\mathrm{M}^{-1} \mathrm{sec}^{-1}$ and $110 \mathrm{sec}^{-1}$, which give a $K_{\mathrm{d}}$ value of $77 \mathrm{~nm}$, corresponding to $\mathrm{pH} 7.2$. consistent with the idea that proton inhibition of whole-cell NMDA receptor responses does not reflect acceleration of ligand unbinding. These data are in agreement with previous data from Yoneda et al. (1994) that suggest that glutamate and glycine binding is $\mathrm{pH}$ independent over a range of $\mathrm{pH}$ 6-9.

Interestingly, the deactivation time course was modestly but significantly accelerated when glycine was removed and $\mathrm{pH}$ was raised (Fig. 3D). Although deactivation time course is complex, one potential explanation could be a modest increase in the dissociation rate for glycine at alkaline $\mathrm{pH}$, which might reflect a slightly lower affinity for glycine when $\mathrm{pH}$ is raised. However, such a hypothetical change in glycine affinity cannot explain the effects of proton inhibition of NMDA receptor function in the presence of saturating glycine and is opposite to the previously reported proton-induced decrease in glycine $\mathrm{EC}_{50}$. (Tang et al., 1990; Traynelis and Cull-Candy, 1991).

\section{Proton association rate}

Small organic molecules diffuse in aqueous solution by obeying Stokes relation and Fick's law as they physically move between two points. In contrast, aqueous proton diffusion can be much faster because protons effectively jump from one water molecule to another through rearrangement of hydrogen bonded networks, rendering proton translocation partly chemical diffusion after a hop and turn Grotthus relay mechanism (Agmon, 1995). Proton wires in gramicidin pore (Akeson and Deamer, 1991; Sagnella et al., 1996; Pomes and Roux, 2002; Pomes and $\mathrm{Yu}, 2003$ ), as well as bacteriorhodopsin (le Coutre and Gerwert, 1996; Sansom, 1998; Luecke and Lanyi, 2003), have served as important models for the study of protonwater interactions within proteins. These and other studies suggest that diffusionlimited proton association rates with ionizable groups within proteins are typically one to four orders of magnitude higher than diffusion-limited association of small molecules, such as neurotransmitters, with their respective binding proteins (Davies et al., 1988; Prod'hom et al., 1987; Kasianowicz and Bezrukov, 1995; Lu and MacKinnon, 1995). To evaluate the proton association rate for NR1/NR2B, outside-out patches expressing NR1/NR2B receptors were lifted into the agonist stream at $\mathrm{pH}$ 6.9, and the solution was rapidly changed to a more alkaline $\mathrm{pH}$ in the continued presence of agonist. The resulting change in current was fitted with an exponential function to 
Table 1. $\mathrm{pH}$-induced current relaxations for NR1/NR2B receptors

\begin{tabular}{lllr}
\hline Jumps from pH 7.9 to & $\tau_{\text {on }}$ (msec) & $\tau_{\text {off }}$ (msec) & $n$ \\
\hline pH 6.4 & $1.6 \pm 0.2$ & $5.2 \pm 1.2$ & 5 \\
pH 6.9 & $3.4 \pm 0.6$ & $4.8 \pm 0.6$ & 12 \\
pH 7.4 & $7.1 \pm 0.7$ & $5.3 \pm 1.3$ & 4 \\
\hline
\end{tabular}

Extracellular $\mathrm{pH}$ was changed during the steady-state response to saturating concentrations of agonists with a rapid application system in outside-out patches from HEK 293 cells expressing NR1/NR2B receptors. Mean \pm SEM; $n$ indicates the number of patches.

measure $\tau_{\text {on }}$ and $\tau_{\text {off }}$ (Fig. $4 A, B$ ). The measured open-tip junction potential for our system had much faster $\tau_{\text {on }}$ and $\tau_{\text {off }}$ (average, $0.4 \pm$ $0.03 \mathrm{msec} ; n=5$ ) than the NMDA receptor-mediated current. Table 1 summarizes the time constants describing the response of the average composite current waveform to changes from $\mathrm{pH} 7.9$ into and out of $\mathrm{pH} 6.4,6.9$, or 7.4. As expected, $\tau_{\text {on }}$ was dependent on proton concentration (Fig. $4 D$ ), whereas $\tau_{\text {off }}$ was $\mathrm{pH}$ independent (Fig. $4 C$ ). The unidirectional rate constants $k_{\text {on }}$ and $k_{\text {off }}$ for proton binding can be estimated from the relationship between proton concentration and $\tau_{\text {on }}$ if a single binding site is assumed to exist for protons (Fig. $4 D$ ). We estimate $k_{\text {on }}$ and $k_{\text {off }}$ to be $1.42 \times 10^{9} \mathrm{M}^{-1} \mathrm{sec}^{-1}$ and 110 $\mathrm{sec}^{-1}$, respectively (Fig. $4 \mathrm{D}$ ). The dissociation rate $k_{\text {off }}$ can be directly estimated from the reciprocal of experimental values of $\tau_{\text {off }}$ and was $196 \mathrm{sec}^{-1}$ by this method. These rates give a $K_{\mathrm{d}}$ value of $77-138 \mathrm{~nm}$ corresponding to $\mathrm{pH} 7.0-7.2$, which is virtually identical to the experimental $\mathrm{IC}_{50}$ values $(\mathrm{pH}$ 6.9-7.1) (Fig. 3E). Association rates derived from macroscopic currents represent a lower limit of the speed at which protons associate and dissociate, because the rate constants we estimated describe only the change in current. These rates do not take into account, for example, any channel-associated delay in reopening or closing after a $\mathrm{pH}$ jump. Thus, the actual microscopic proton association and dissociation rates are likely to be somewhat faster.

\section{Proton-induced changes in single-channel properties}

Changes in the extracellular $\mathrm{H}^{+}$concentration alter neuronal NMDA channel opening frequency without changing unitary conductance or the open-channel dwell times (Tang et al., 1990, Traynelis and Cull-Candy, 1991). One interpretation of these data are that the proton block of NMDA receptors reflects a change in the opening rate and thus a change in open probability $\left(P_{\mathrm{o}}\right)$. To directly measure $P_{\mathrm{o}}$, we recorded the response to brief application of a saturating concentration $(1 \mathrm{~mm})$ of glutamate and counted in each sweep the maximum number of channels that were simultaneously open at different $\mathrm{pH}$ values (Fig. $5 A, B$ ). For each patch with only one apparent active channel, the fraction of records with any openings in response to 1-8 msec application of $1 \mathrm{~mm}$ glutamate was determined; we only included patches with at least 20 sweeps (average of 90 per patch). If we assume that NR1/NR2B receptors always bind glutamate under these conditions, then this value corresponds to the probability that an agonist-bound receptor will open at least once before the receptor desensitizes or agonist unbinds, which we refer to as $P_{\text {o(burst) }}$. The probability that agonist binding will trigger a burst of openings was $0.43 \pm 0.03(\mathrm{pH} 6.9 ; n=12), 0.54 \pm 0.05(\mathrm{pH}$ $7.4 ; n=10)$, and $0.71 \pm 0.08(\mathrm{pH} 7.9 ; n=5)$ (Fig. $5 C$ ). We also calculated the open probability at the peak of the response, or $P_{\text {o(peak) }}$, by averaging all records from each patch and then dividing the mean peak current by the unitary current amplitude $\left(V_{\mathrm{HOLD}},-100 \mathrm{mV}\right)($ Fig. $5 C) . P_{\mathrm{o}(\text { peak })}$ was $0.11 \pm 0.02(\mathrm{pH} 6.9$; $n=11), 0.18 \pm 0.01(\mathrm{pH} 7.4 ; n=8)$, and $0.24 \pm 0.02(\mathrm{pH} 7.9 ; n=$ $8)$. These data fit well with previous estimates of NR1/NR2B open probability at $\mathrm{pH} 7.4\left[P_{\mathrm{o} \text { (peak) }}=0.17 ; P_{\mathrm{o} \text { (burst) }}=0.47\right.$ (Banke and Traynelis, 2003)]. Moreover, the homogenous open probability
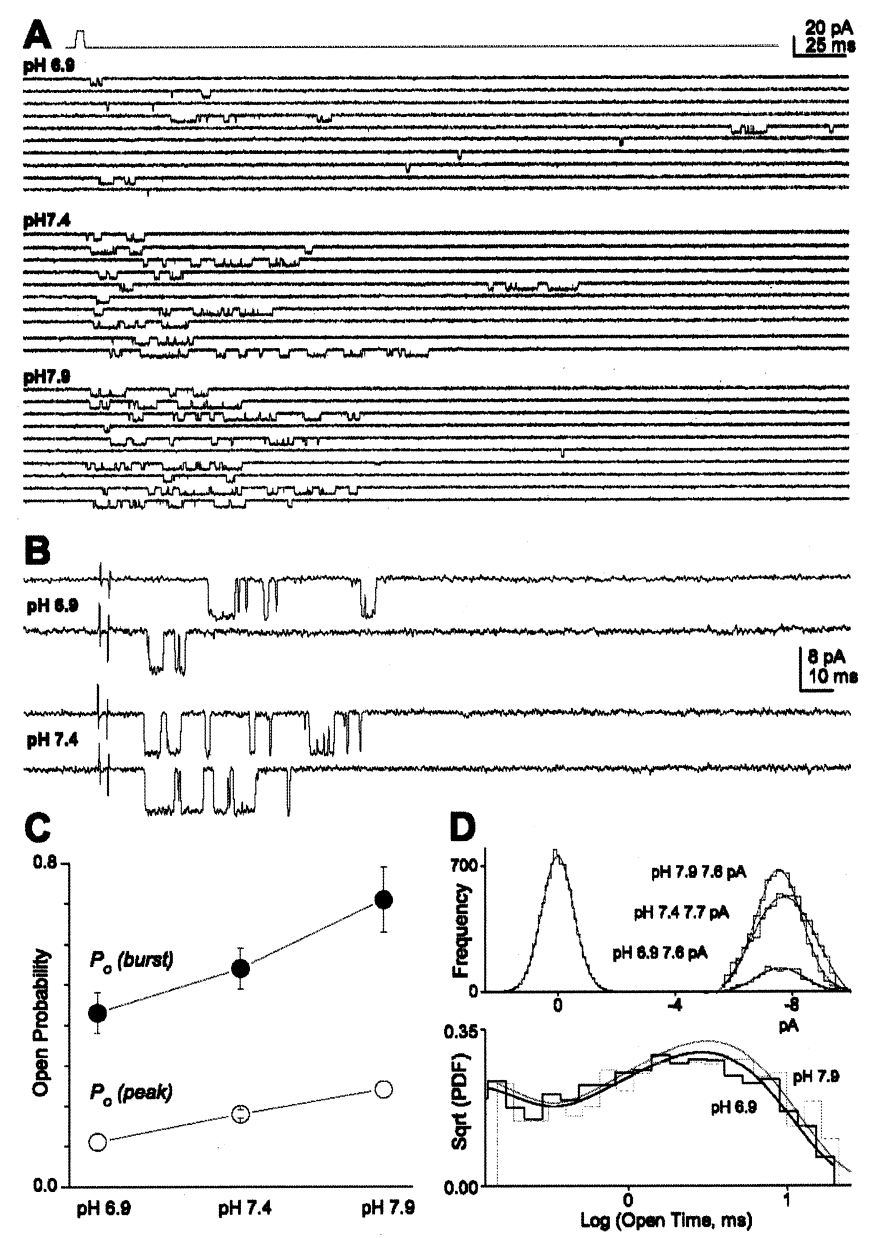

Figure 5. Proton binding decreases NR1/NR2B open probability. $A, B$, Patches were pulled from HEK 293 cells expressing NR1/NR2B and stimulated with a brief (1- $4 \mathrm{msec}) 1 \mathrm{~mm}$ glutamate pulse (top) at pH 7.9, 7.4, and 6.9, as indicated. All responses in $A$ and $B$ are from the same patch, which contained only a single active channel. Responses in $B$ are shown on an expanded time scale. $C$, Peak open probability, $P_{\text {o(peak) }}$, was calculated at each $\mathrm{pH}$ by averaging all traces and then dividing by the measured unitary current amplitude $\left(V_{\text {HOLD }},-100 \mathrm{mV}\right)$. Probability that agonist binding induces a burst, $P_{0 \text { (burst) }}$, was defined as the proportion of binding events that lead to at least one channel activation and similarly varied with $\mathrm{pH}$. Only patches with one active channel were analyzed; a subset $(n=6)$ of the patches at pH $7.4(n=10)$ were also described by Banke and Traynelis, 2003. D, Top, The same conductance level was observed at the three $\mathrm{pH}$ values tested under our recording conditions (see Materials and Methods). The results are shown for the patch in $A$ as an all-points histogram. The average chord conductance at $-100 \mathrm{mV}$ was $68 \pm 4.1 \mathrm{pS}(\mathrm{pH} \mathrm{6.9)}, 72 \pm 5.2 \mathrm{pS}(\mathrm{pH} 7.4)$, and $75 \pm 5.8 \mathrm{pS}(\mathrm{pH} 7.9 ; n=$ $4-5 ; p=0.640$; ANOVA). Bottom, Open-time histograms for the patch in $A$ [square root of the probability density function, or Sqrt(PDF)] from brief concentration jump experiments at pH 7.9 (809 events) and 6.9 (759 events) are superimposed. Fitted time constants for this histogram were $\tau_{\text {fast }} 77,81 \mu \mathrm{sec}$ (area 34, 26\%) and $\tau_{\text {slow }} 2.9,3.3 \mathrm{msec}$ for $\mathrm{pH} 6.9$ and 7.9, respectively.

among patches and twofold increase in peak open probability in patches with two active channels $(n=6$; data not shown) were consistent with our interpretation that we can identify patches that contain only one active channel. In addition, $P_{\mathrm{o} \text { (peak) }}$ at $\mathrm{pH}$ 6.9 is close to $50 \%$ of the maximum value at $\mathrm{pH} 7.9$, in agreement with concentration-response measurements in patches from HEK 293 cells that predict slightly $>50 \%$ inhibition (Fig. 3E). Finally, single-channel conductance for NR1/NR2B did not change significantly over the $\mathrm{pH}$ range tested (Fig. $5 \mathrm{C}$ ). Moreover, the degree of proton inhibition of steady-state whole-cell responses at $\mathrm{pH} 6.4$ was identical at -50 and $+50 \mathrm{mV}(n=5$; data not shown).

Our recordings of experimentally defined activations from 
Table 2. Open-time parameters for NR1/NR2B channels activated by glutamate

\begin{tabular}{|c|c|c|c|c|c|}
\hline $\mathrm{pH}$ & $\begin{array}{l}\text { Mean open-time (msec) } \\
\text { brief application }\end{array}$ & $\begin{array}{l}\text { Mean open-time (msec) } \\
\text { continuous application }\end{array}$ & $\begin{array}{l}\tau_{1}(\mathrm{msec}) \text { continuous } \\
\text { application }\end{array}$ & $\begin{array}{l}\text { Area } 1(\%) \text { continuous } \\
\text { application }\end{array}$ & $\begin{array}{l}\tau_{2}(\mathrm{msec}) \text { continuous } \\
\text { application }\end{array}$ \\
\hline 6.4 & & $2.96 \pm 0.32$ & 0.07 & 28 & 2.9 \\
\hline 6.9 & $2.5 \pm 0.23$ & $2.82 \pm 0.32$ & 0.07 & 36 & 3.2 \\
\hline 7.4 & $3.3 \pm 0.17^{*}$ & $3.28 \pm 0.38$ & 0.07 & 40 & 3.4 \\
\hline 7.9 & $3.5 \pm 0.28^{*}$ & $3.48 \pm 0.51$ & 0.07 & 45 & 3.9 \\
\hline
\end{tabular}

Five outside-out patches expressing one detectable NR1/NR2B receptor were stimulated with $1-4$ msec pulses (13-40 kHz, $5 \mathrm{kHz},-3 \mathrm{~dB}$ filter) of $1 \mathrm{~mm}$ glutamate. Data were obtained in each patch at three different $\mathrm{pH}$ values $(6.9,7.4$, and 7.9$)$. Total number of openings was 1060,4125 , and 1606 at pH 6.9 7.4 , and 7.9, respectively. Responses from a different set of five to eight patches with one to two active channels were also recorded in response to continuous application of glutamate $(20-40 \mathrm{kHz}, 5 \mathrm{kHz}$ filter, $-3 \mathrm{~dB}$ ). A resolution of $100 \mu$ sec was imposed on the data. Composite histograms for channel response to continuous application of agonist comprised 2274, 3093, 6495, and 2940 events for pH values of 6.4,6.9, 7.4, and 7.9, respectively. ${ }^{*} p<0.02$, significantly different from values at $\mathrm{pH} 6.9$ (ANOVA; Tukey's post hoc test).

A

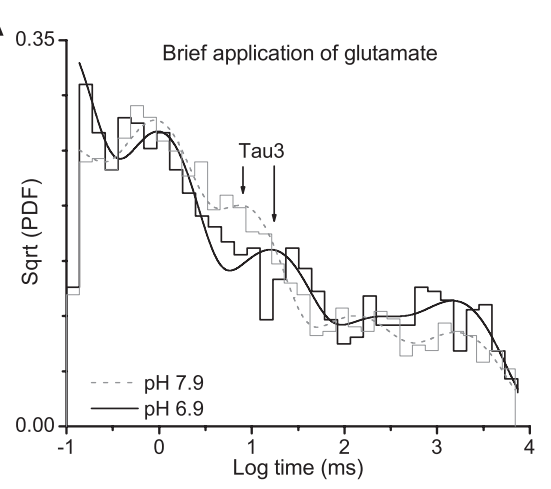

$\mathbf{B}_{0}$

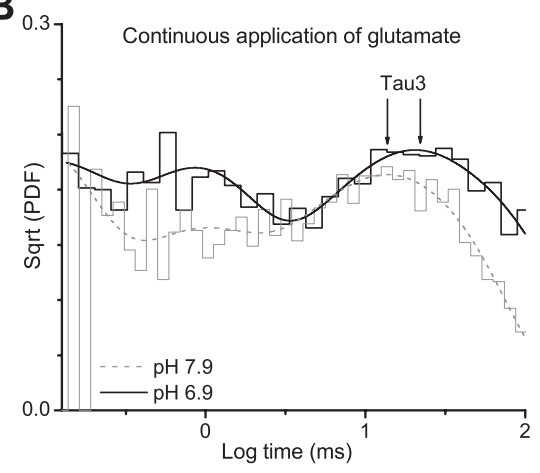

Figure 6. Protonation of NR1/NR2B channels alters the shut-time histogram. $A$, Outside-out patches containing NR1/NR2B receptor channels were stimulated with brief $1-8 \mathrm{msec}$ pulses (patches contained 1 active channel) of $1 \mathrm{~mm}$ glutamate at pH 6.9 and 7.9; glycine at $20 \mu \mathrm{m}$ was present in all solutions. Composite shut-time distributions [square root of the probability density function, or Sqrt(PDF)] from $10(\mathrm{pH} \mathrm{6.9)}$ and 5 ( $\mathrm{pH} \mathrm{7.9)}$ patches in response to rapid glutamate application were fitted with five exponential components (for values, see Table 3). B, Glutamate at $1 \mathrm{~mm}$ ( $20 \mu \mathrm{m}$ glycine) was continuously applied to patches that contained one to two active channels at pH 6.9 and 7.9. Composite shut-time distributions from $10(\mathrm{pH} 6.9)$ and 6 (pH 7.9) patches in response to rapid application were fitted with five exponential components (for values, see Table 3 ). The longest shut-time components, which contain closed periods during which receptors in desensitized state(s) as well as periods intervening between opening of two independent channels, are not shown. Arrows illustrate $\mathrm{pH}$-dependent changes in the intermediate $\tau_{3}$. A resolution of $100 \mu \mathrm{sec}$ was imposed on the data, which was digitized at $13-40 \mathrm{kHz}$ ( $5 \mathrm{kHz}$ filter, $-3 \mathrm{~dB}$ ).

individual NR1/NR2B receptors allow an unambiguous definition of intraburst open and closed lifetimes for a fully liganded receptor. Most patches were recorded under at least two different $\mathrm{pH}$ values, one of which was always $\mathrm{pH}$ 7.4. Idealized openings from single-channel patches were pooled, and the open and shuttime distribution were best fitted with the sum of two and five exponential components, respectively (see Materials and Methods). In a subset of responses recorded in one channel patch in response to brief application of glutamate at three different $\mathrm{pH}$ values, we detected a modest $29 \%$ decrease in mean open time at pH 6.9 compared with 7.9 (ANOVA; Tukey's post hoc test) (Table 2 ). We could not detect any significant change in mean open time from a different set of channels in multiple patches recorded in response to continuous application of agonist at different $\mathrm{pH}$ values, perhaps attributable to the small effect and patch-topatch variability. These data suggest that protons may modestly decrease the response of the macroscopic current in part through reduction in open time.

Shut-time histograms were best fit by the sum of five exponential components. We proposed previously (Banke and Traynelis, 2003) that the slowest component of the shut-time histogram $(>1000 \mathrm{msec})$ represents the recovery of receptors from a desensitized state, whereas a very fast flicker $\left(\tau_{1}<0.1\right.$ $\mathrm{msec}$ ) may reflect pore dilation or a brief-lived blocked state (Kleckner and Pallotta, 1995; Popescu and Auerbach, 2003; Banke and Traynelis, 2003). Neither of these components ap- peared sensitive to extracellular protons (Fig. 6A, Table 3). Two closed-time components $\left(\tau_{2} \sim 1\right.$ and $\left.\tau_{3} \sim 10 \mathrm{msec}\right)$ were suggested previously to primarily reflect two kinetically distinct conformational changes that precede gating, one of which is sensitive to glycine partial agonists, whereas the other is sensitive to glutamate partial agonists (Banke and Traynelis, 2003). Slowing either of these pregating steps will reduce the macroscopic current. We found that only the third shut-time component $\left(\tau_{3}\right)$ appears to be slowed from 7.3 to $14 \mathrm{msec}$ (192\% change) when the channels have been challenged by a brief pulse of glutamate and glycine at $\mathrm{pH} 7.9$ versus pH 6.9 (Fig. 6A, Table 3 ). The second time constant $\left(\tau_{2}\right)$ was insensitive to protons.

One limitation with the approach used here is the difficulty in obtaining patches with only a single active channel present when stimulated for brief duration with saturating concentration of both glutamate and glycine (Gibb, 2004). In addition, we digitized a long enough period $(8-13 \mathrm{sec})$ to allow for recovery from desensitization, which further reduces the total number of events that can be obtained to less than five activations per minute of recording. Because NR1/NR2B channels only open half of the time that they bind agonist (Banke and Traynelis, 2003), we could record at most two to three activations per minute. To confirm the effects of protons on single-channel gating, we also analyzed single apparent activations in response to continuous application of saturating concentrations of agonists in patches that contained at most one to two channels (Table 3). This recording paradigm allows us to obtain more open and closed transitions per patch. However, the presence of multiple channels in the patch restricts our interpretation to the three fastest shut-time components that are unambiguously within activations. Because glutamate and glycine are continuously present, the channels spend more time in desensitized states, which can be used to separate activations. The three fastest fitted time constants were virtually identical between patches exposed to brief and continuous glutamate and glycine (Table 3 ). $\tau_{3}$ describing shut-time histograms for responses to continuous agonist application was slowed from $8.7 \mathrm{msec}$ at $\mathrm{pH} 7.9$ to $15.6 \mathrm{msec}$ at pH 6.4 (179\% change).

\section{Mechanism of proton block of NR1/NR2B receptors}

How can we reconcile these data with a physical model of receptor function that includes explicit protonated conformations? A key feature of our data is the lack of effect of protons on the macroscopic time course of the current despite the strong and ultimately complete inhibition of receptor function by protons. Furthermore, we showed that protons do not block glutamate or glycine binding. Our data suggest that, even when receptors are protonated, they continue to bind and release agonists, as well as desensitize and recover from desensitization with similar rate 
Table 3. Shut-time parameters for NR1/NR2B channels activated by glutamate

\begin{tabular}{|c|c|c|c|c|c|c|c|c|c|}
\hline & Glutamate application & pH 6.4 (msec) & Area (\%) & pH 6.9 (msec) & Area (\%) & pH 7.4 (msec) & Area (\%) & pH 7.9 (msec) & Area (\%) \\
\hline$\tau_{1}$ & $1-8 \mathrm{msec}$ & & & 0.07 & 48 & 0.07 & 35 & 0.07 & 24 \\
\hline$\tau_{2}$ & $1-8 \mathrm{msec}$ & & & 0.89 & 32 & 0.75 & 36 & 0.76 & 42 \\
\hline$\tau_{3}$ & $1-8 \mathrm{msec}$ & & & 14.0 & 11 & 8.8 & 24 & 7.3 & 24 \\
\hline$\tau_{4}$ & $1-8 \mathrm{msec}$ & & & 136 & 3 & 100 & 3 & 113 & 5 \\
\hline$\tau_{5}$ & $1-8 \mathrm{msec}$ & & & 1467 & 6 & 2023 & 2 & 1588 & 5 \\
\hline$\tau_{1}$ & Continuous & 0.07 & 35 & 0.07 & 32 & 0.07 & 45 & 0.07 & 44 \\
\hline$\tau_{2}$ & Continuous & 0.76 & 35 & 0.74 & 28 & 0.73 & 22 & 0.73 & 15 \\
\hline$\tau_{3}$ & Continuous & 15.6 & 9 & 12.3 & 17 & 8.9 & 14 & 8.7 & 16 \\
\hline
\end{tabular}

Composite shut-time histograms from $6-12$ patches were fitted with the sum of multiple-exponential functions. $\tau_{3}$ values are shown in bold. Composite histograms comprised 1072,3633 , and 1478 events in pH $6.9,7.4$, and 7.9 for brief agonist application and 1969, 2774, 5950, and 2708 events (4 patches) in $\mathrm{pH} 6.4,6.9,7.4$, and 7.9 for continuous agonist application. A resolution of $100 \mu$ sec was imposed on the data.

constants. We propose that once protons dissociate, the receptor continues its already in-progress normal response time course. We hypothesize that protonated receptors only differ from unprotonated receptors in that they cannot open. Similar arguments have been proposed for selective proton effects on a single unidirectional rate constant for mechanosensitive channels (Guharay and Sachs, 1985). This proposed effect of protons on the opening rate is consistent with previous suggestions that protons act in the linker region (Low et al., 2003) proposed to couple the effects of agonist binding to the S1S2 domain to the transmembrane pore-forming elements that perform gating (Jones et al., 2002; Sobolevsky et al., 2002). Figure 7 illustrates a set of physical models of NMDA receptor gating in which the receptor can bind a proton anywhere along the reaction pathway, except during pregating steps required for activation. Multiple closed and protonated conformations exist because the proton site is independent of glutamate binding and desensitization.

We subsequently evaluated this conceptual model, with the goal not being the identification of the optimal set of rate constants that perfectly reproduce the data. Rather, we used this model to ask several conceptual questions about how proton binding might cause inhibition of receptor function. We assume the underlying model for channel activation in the absence of protons, adapted from Banke and Traynelis (2003) and Popescu and Auerbach (2003), to be a reasonable first pass approximation of channel function (Gibb, 2004). We omitted any partially protonated states that might occur if the proton sensor exists on multiple subunits and might have intermediate properties, although we cannot rule out this possibility. We also show for simplicity only a single open state rather than multiple open states (Table 2) (Popescu and Auerbach, 2003) and have neglected to show protonation of the open state. This model does not include short-lived shut states and thus cannot reproduce the fastest component of the shut-time distribution.

To evaluate how protons alter gating, we evaluated how well each of the three schemes could predict the sequence of openings and closings in response to brief agonist application at three dif-

C

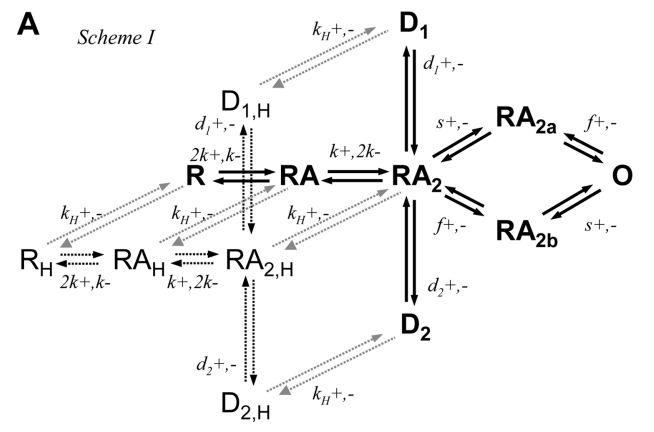

7. A physical model of pH inhibition of the NR1/NR2B NMDA receptor. $A$, Each NMDA receptor complex is assumed to and $\mathrm{RA}_{2} \mathrm{~b}$ indicates closed receptors that have undergone either the slow (NR2 subunit-dependent) or fast (NR1 subunitcol eceptor. C, Maximum likelihood fits of each model to the sequence of open and closed receptors determined at three different $\mathrm{pH}$ same. The proton dissociation rate was fixed to be $196 \mathrm{sec}^{-1}$, and thus all models have nine free parameters. Fitting omitted glutamate and glycine binding steps.

ferent $\mathrm{pH}$ values ( $n=6-11$ patches). The schemes differ only in the extent to which they allow protonated receptors to undergo what we hypothesize to be conformational changes that are required for gating. Experimentally defined channel activations in response to brief agonist application to patches with a single active channel were analyzed starting and ending in the first and last opening to remove agonist binding steps. Each model was simultaneously fitted to the sequence of openings and closings for all patches at all $\mathrm{pH}$ values using maximum likelihood methods (QUB software). Scheme II was superior in terms of the maximum likelihood value (Figs. 7C, 8A), with the log likelihood being 12-19 units higher than other schemes. We subsequently 

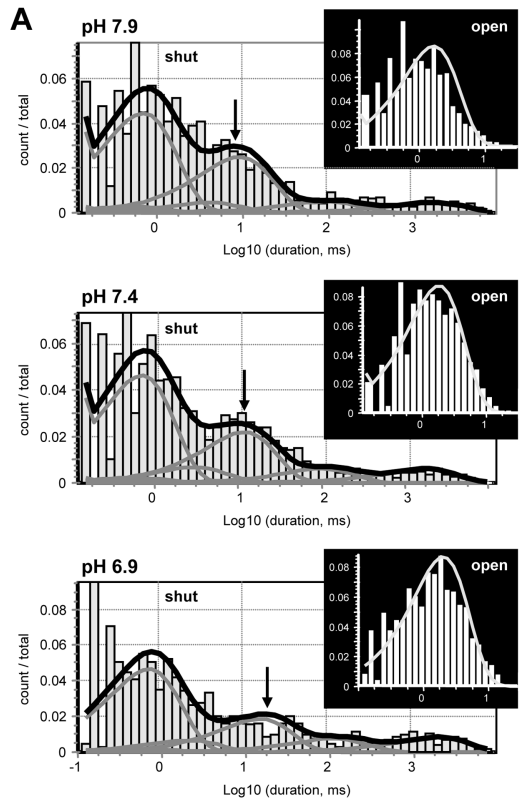

B
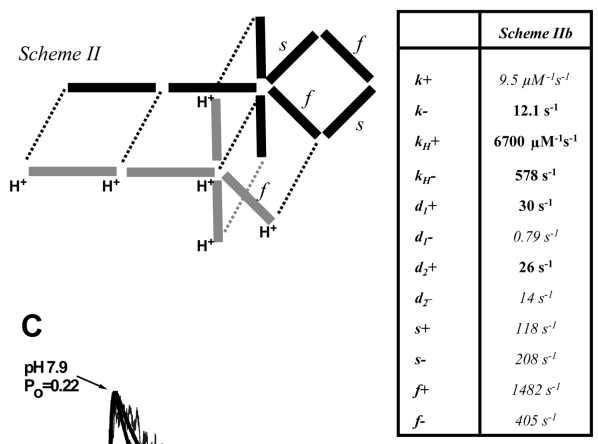

C

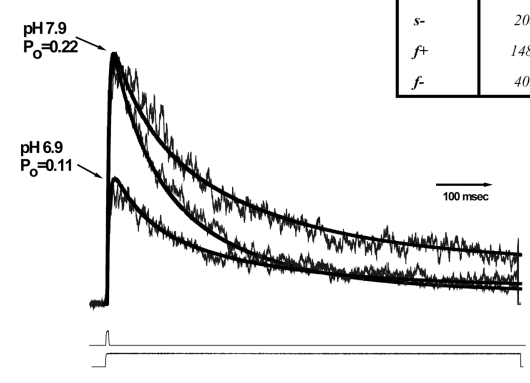

Figure 8. Fitting physical models of $\mathrm{H}^{+}$inhibition of NR1/NR2B receptors to single-channel and macroscopic data. A, Theoretical shut- and open-time probability density function predicted by maximum likelihood fit of scheme ll to the sequence of open and closed events for all patches at three $\mathrm{pH}$ values are superimposed on histograms generated from data. Arrows show shift in $\tau_{3}$ describing the shut-time distribution. $B$, Schematic illustration of the connectivity of the various states in the receptor for scheme $\mathrm{llb}$. Values to the right are rate constants obtained by least-squares fitting of the current model to a series of macroscopic recordings obtained at $\mathrm{pH} 6.9$ and 7.9 in response to maximal concentrations of glutamate applied for brief ( $1-8 \mathrm{msec}$ ) and long $(>1 \mathrm{sec}$ ) duration. Five parameters (in bold) were allowed to vary. Others were set to those determined by maximum likelihood fitting (Fig. 7, Scheme II). C, Macroscopic currents predicted from the fitted rate constants are superimposed on the data set.

used the QUB-derived gating constants to simulate a wide range of macroscopic parameters to evaluate model performance. Scheme II (but not schemes I and III) was able to qualitatively reproduce the main observations obtained for both microscopic and macroscopic data, in particular the apparent proton-induced slowing of $\tau_{3}$ in the shut-time histogram (Fig. $8 \mathrm{~A}$ ), the $\mathrm{pH}$ induced slowing of the rise time (Fig. 2), the $\mathrm{pH}$-dependent and $\mathrm{pH}$-independent relaxations in the presence of agonist (Fig. 4), and the proton $\mathrm{IC}_{50}(\mathrm{pH} 7.0)$. Because the macroscopic data we obtained contains additional information about the proton sensitivity and desensitization times, we refitted scheme II to a set of average NR1/NR2B macroscopic responses to prolonged or brief application of glutamate to better estimate desensitization parameters and proton association and dissociation rates. In scheme IIb, we held rates determined for gating, agonist binding, and recovery from desensitization constant. Figure $8 \mathrm{~B}$ confirms that this model was able to qualitatively predict the essential features of macroscopic channel activation and desensitization (Fig. 8C).

\section{Discussion}

The experiments described here suggest that the inhibitory actions of extracellular protons at a defined NMDA receptor (NR1/ NR2B) do not occur at either glutamate or glycine binding site (Figs. 1, 3) and do not alter deactivation, desensitization, or single-channel conductance. We demonstrate a clear effect on single-channel open probability (Fig. 5) with only modest proton effects on mean channel open time (Fig. 5, Table 2). In addition, we observe a proton-induced slowing of one component of the shut-time histogram and of both the activation rate for macroscopic currents and the first latency to channel opening (Figs. 2, 6). We define the time frame under which protons act (Fig. 4) and estimate that the macroscopically derived proton association rate $\left(1.42 \times 10^{9} \mathrm{M}^{-1}\right.$ $\left.\mathrm{sec}^{-1}\right)$ is faster than the diffusion limit for small molecules $\left(\sim 1 \times 10^{8} \mathrm{M}^{-1} \mathrm{sec}^{-1}\right)$, consistent with proton actions in other proteins. The proton dissociation rate $\left(110-196 \mathrm{sec}^{-1}\right)$ suggests a mean duration for the protonated state of 5-9 msec. We present a simple model in which protonated receptors can bind agonist but cannot open. This model can reproduce all of our findings and suggests that channel activation and gating are tightly coupled to the protonation state of key residues in the receptor.

\section{Structural implications}

Although the idea that each ionizable residue within a protein constitutes a proton binding site with rate constants defining the $\mathrm{pKa}$ is a well known biochemical principle, the location and function of residues that create the proton sensitivity on the NMDA receptor is not well understood. Many features of proton-sensitive gating appear to be conserved across GluR subfamilies (Christensen and Hida, 1990; Traynelis and Cull-Candy, 1991; Traynelis and Heinemann, 1995; Wu and Christensen, 1996; Mott et al., 2003; Cui and Mayer, 2001). Mutagenesis work together with homology modeling of the extracellular domains of the NR1 subunit suggest that residues at which substitutions strongly influence proton-sensitive gating cluster in two regions, both of which reside close to the linker connecting the agonist binding domain to transmembrane pore-forming elements (Low et al., 2003). This region is ideally localized to influence the coupling of agonist binding to channel activation (Kohda et al., 2000; Jones et al., 2002; Sobolevsky et al., 2002). However, it remains unclear whether the structural elements formed by this linker region comprise or contribute to the proton sensor or whether this result instead reflects reciprocal interactions between the gating machinery and a distant and as yet unidentified proton sensor. One important possibility yet to be raised in the literature that is consistent with the tight functional coupling we see between protons and gating is the idea that NMDA receptor activation involves deprotonation of a residue that, when protonated, stabilizes the closed state.

Extensive mutagenesis throughout most of the extracellular regions of the NR1 protein such as the agonist binding domain and the $\mathrm{N}$-terminal domain is without effect on $\mathrm{pH}$-sensitive gating (Low et al., 2003). This result is consistent with the lack of effect of $\mathrm{pH}$ on experimentally determined coagonist dose-response relationships (Tang et al., 1990; Traynelis and CullCandy, 1990,1991), the current relaxation time course after agonist removal (Fig. 1), and on agonist ionization (glutamate and glycine pKa values are 2.2, 4.3, 9.7 and 2.4, 9.8, respectively). Figure 3 further supports this idea by showing that proton sensitivity is identical in the absence or presence of glutamate and glycine, which eliminates the possibility that inhibition reflects the inability of receptors to bind agonist while protonated. Where is the proton sensor and what might it look like? Several clues have emerged from work on other channels. Potassium channels 
and glutamate receptors are thought to share a common transmembrane architecture (Wood et al., 1995; Kuner et al., 2003; Sobolevsky et al., 2003), suggesting that the mechanism by which protons modulate these channels could be similar. Schulte et al. (2001) have suggested that a close interaction exists between a proton sensor outside the pore and gating of Kir channels (Ruppersberg, 2000). The proton inhibition of Kir1.1 is driven by protonation of the amino group of a lysine residue in the intracellular N-terminal domain (corresponds to extracellular $\mathrm{N}$-terminal domain in NMDA receptors) that lies in close proximity to the first transmembrane elements. The $\mathrm{pKa}$ of this group is proposed to be influenced by other positively charged residues that are forced into proximity by tertiary structure of the channel complex (Schulte et al., 1999). L-type $\mathrm{Ca}^{2+}$ and cyclic nucleotide-gated channels are similarly controlled by protons, and similar mechanisms have been proposed (Root and MacKinnon, 1994; Chen et al., 1996). In each of these channels, the working hypothesis is that the pKa of a critical residue is shifted to physiological range by the repulsive forces of either ionized carboxylic acids or amino/guanidino groups located at some distance within the polypeptide chain but forced close together by tertiary structure, illustrating how the proton sensor might be a multipart entity. Such an arrangement is well poised to control conformational motions within a large protein complex.

\section{Mechanism of proton block of NMDA receptors}

Most proton concentration-response data argue for a single ionizable residue whose protonation causes complete channel inhibition. We therefore assume that a single proton sensor exists or that multiple sensors with similar $\mathrm{pKa}$ values exist in individual subunits or subunit dimers. This assumption allows us to estimate the proton association rate $\left(1.4 \times 10^{9} \mathrm{M}^{-1} \mathrm{sec}^{-1}\right)$, which is $>100$ times faster than the glutamate association rate and similar to that found in Kir $\left[1.9 \times 10^{9} \mathrm{M}^{-1} \mathrm{sec}^{-1}\right.$ (Lu and MacKinnon, 1995)], strengthening the potential parallels in proton gating between these two channels. NMDA receptor proton association is slower than that for $\alpha$-toxin ion channel and proton-gated channels in chick dorsal root ganglion cells $\left[8 \times 10^{9} \mathrm{M}^{-1} \mathrm{sec}^{-1}(\mathrm{Ka}-\right.$ sianowicz and Bezrukov, 1995; Davies et al., 1988)] and $\sim 100$ times slower than the protonation rate for a proton-gated $\mathrm{Na}^{+}$permeable channel (Prod'hom et al., 1987). This could indicate that protonation of NMDA receptors is not a first-order process, that the proton sensor is accessible by a water wire within the protein (Sansom, 1998; Luecke and Lanyi, 2003), or that only certain protein conformations are available for protonation (Fig. 7B).

We propose that protonation creates the possibility for hydrogen or ionic bonds that increase the activation energy for a conformational change that precedes pore dilation (Ludwig et al., 2003). We note the energy of a single hydrogen bond (3-5 kcal/ $\mathrm{mol}$ ) is larger than that associated with a 10-fold change in an equilibrium constant for two states $(1.4 \mathrm{kcal} / \mathrm{mol})$. Blockade of a single step by protonation will change the overall exit rate from the gateway closed state and thus change its free energy. Such an effect of protonation is conceivable if the proton sensor lies in the linker regions that translate agonist binding to channel activation. The effects of protonation as represented in schemes II and IIb (Figs. 7, 8) occur intuitively because protonation locks the channel into a nonconducting mode on average for 5-9 msec until the proton dissociates. This delay can occur from almost any state, and, when it occurs en route to activation, it slows the response rise time. Moreover, simulations confirm that entry into a protonated state after channel closure can prolong the closure, thereby adding an additional shut-time component that appears as a slowing of $\tau_{3}$. Thus, this transient occupancy of the nonconducting states can account for both microscopic and macroscopic features of proton inhibition.

\section{Conclusions}

The data presented here have led to the idea that protons selectively inhibit NR1/NR2B channel opening, which fits nicely with an increasing understanding of the proton sensor localization. This conclusion emphasizes the tight coupling between channel gating and the proton sensor and excludes a number of other hypothetical mechanisms for proton inhibition. However, several caveats remain. Although we can find no other hidden Markov model that will reproduce all of our data, we have not exhaustively explored all possible hypothetical actions of protons. Moreover, we oversimplified our gating scheme to represent only the main features resolved within our data and asked only a limited set of questions through modeling. We also do not know the molecular basis of proton binding. Despite these caveats, our findings provide a straightforward and intuitive working hypothesis about how protonation could control NMDA receptor function that can be directly envisioned as a physical model. The finding that protons appear to shift receptors to an inactive state also carries structural implications and suggests that other forms of allosteric modulation could proceed through creation of briefly occupied inactive states [e.g., calcineurin effects on GluR1 (Banke et al., 2000)]. Given that a number of regulators, such as polyamines, extracellular $\mathrm{Zn}^{2+}$, ifenprodil, and alternative splicing, all appear to alter NMDA receptor function by shifting the pKa of the proton sensor (Traynelis et al., 1995; Mott et al., 1998; Choi and Lipton, 1999; Low et al., 2000), our findings have widespread implications for NMDA receptor function.

\section{References}

Agmon N (1995) The Grotthus mechanism. Chem Phys Lett 244:456-462. Akeson M, Deamer DW (1991) Proton conductance by the gramicidin water wire. Model for proton conductance in the F1F0 ATPases? Biophys J 60:101-109.

Balestrino M, Somjen GG (1988) Concentration of carbon dioxide, interstitial $\mathrm{pH}$ and synaptic transmission in hippocampal formation of the rat. J Physiol (Lond) 396:247-266.

Banke TG, Traynelis SF (2003) Activation of NR1/NR2B NMDA receptors. Nat Neurosci 6:144-152.

Banke TG, Bowie D, Lee H, Huganir RL, Schousboe A, Traynelis SF (2000) Control of GluR1 AMPA receptor function by cAMP-dependent protein kinase. J Neurosci 20:89-102.

Chen C, Okayama H (1987) High-efficiency transformation of mammalian cells by plasmid DNA. Mol Cell Biol 7:2745-2752.

Chesler M, Kaila K (1992) Modulation of pH by neuronal activity. Trends Neurosci 15:396-402.

Choi YB, Lipton SA (1999) Identification and mechanism of action of two histidine residues underlying high-affinity $\mathrm{Zn}^{2+}$ inhibition of the NMDA receptor. Neuron 23:171-180.

Christensen BN, Hida E (1990) Protonation of histidine groups inhibits gating of the quisqualate/kainate channel protein in isolated catfish cone horizontal cells. Neuron 5:471-478.

Colquhoun D, Sigworth FJ (1995) Fitting and statistical analysis of singlechannel records in single-channel recording, Ed 2 (Sakmann B, Neher E, eds), pp 483-585. New York: Plenum.

Cui C, Mayer ML (2001) Gating mechanisms of GluR0. Soc Neurosci Abstr 27:481.16.

Danysz W, Parsons CG (2002) Neuroprotective potential of ionotropic glutamate receptor antagonists. Neurotox Res 4:119-126.

Davies NW, Lux HD, Morad M (1988) Site and mechanism of activation of proton-induced sodium current in chick dorsal root ganglion neurones. J Physiol (Lond) 400:159-187.

Dingledine R, Borges K, Bowie D, Traynelis SF (1999) The glutamate receptor ion channels. Pharmacol Rev 51:7-61. 
Erreger K, Chen P, Wyllie DJA, Traynelis SF (2004) Activation and gating of ionotropic glutamate receptors. Crit Rev Neurobiol, in press.

Gibb AJ (2004) NMDA receptor subunit gating- uncovered. Trends Neurosci 27:7-10, discussion 10 .

Giffard RG, Monyer H, Christine CW, Choi DW (1990) Acidosis reduces NMDA receptor activation, glutamate neurotoxicity, and oxygen-glucose deprivation neuronal injury in cortical cultures. Brain Res 506:339-342.

Guharay F, Sachs F (1985) Mechanotransducer ion channels in chick skeletal muscle: the effects of extracellular pH. J Physiol (Lond) 363:119-134.

Hirano A, Moridera N, Akashi M, Saito M, Sugawara M (2003) Imaging of L-glutamate fluxes in mouse brain slices based on an enzyme-based membrane combined with a difference-image analysis. Anal Chem 75:3775-3783.

Jones KS, VanDongen HM, VanDongen AM (2002) The NMDA receptor M3 segment is a conserved transduction element coupling ligand binding to channel opening. J Neurosci 22:2044-2053.

Kaku DA, Giffard RG, Choi DW (1993) Neuroprotective effects of glutamate antagonists and extracellular acidity. Science 260:1516-1518.

Kasianowicz JJ, Bezrukov SM (1995) Protonation dynamics of the alphatoxin ion channel from spectral analysis of $\mathrm{pH}$-dependent current fluctuations. Biophys J 69:94-105.

Kemp JA, McKernan RM (2002) NMDA receptor pathways as drug targets. Nat Neurosci [Suppl] 5:1039-1042.

Kleckner NW, Pallotta BS (1995) Burst kinetics of single NMDA receptor currents in cell-attached patches from rat brain cortical neurons in culture. J Physiol (Lond) 486:411-426.

Kohda K, Wang Y, Yuzaki M (2000) Mutation of a glutamate receptor motif reveals its role in gating and delta2 receptor channel properties. Nat Neurosci 3:315-322.

Kohl BK, Dannhardt G (2001) The NMDA receptor complex: a promising target for novel antiepileptic strategies. Curr Med Chem 8:1275-1289.

Kuner T, Seeburg PH, Guy HR (2003) A common architecture for $\mathrm{K}^{+}$channels and ionotropic glutamate receptors? Trends Neurosci 26:27-32.

le Coutre J, Gerwert K (1996) Kinetic isotope effects reveal an ice-like and a liquid-phase-type intramolecular proton transfer in bacteriorhodopsin. FEBS Lett 398:333-336.

Lester RA, Jahr CE (1992) NMDA channel behavior depends on agonist affinity. J Neurosci 12:635-643.

Low CM, Zheng F, Lyuboslavsky P, Traynelis SF (2000) Molecular determinants of coordinated proton and zinc inhibition of $N$-methyl-D-aspartate NR1/NR2A receptors. Proc Natl Acad Sci USA 97:11062-11067.

Low CM, Lyuboslavsky P, French A, Le P, Wyatte K, Thiel WH, Marchan EM, Igarashi K, Kashiwagi K, Gernert K, Williams K, Traynelis SF, Zheng F (2003) Molecular determinants of proton-sensitive N-methyl-Daspartate receptor gating. Mol Pharmacol 63:1212-1222.

Lu Z, MacKinnon R (1995) Probing a potassium channel pore with an engineered protonatable site. Biochemistry 34:13133-13138.

Ludwig MG, Vanek M, Guerini D, Gasser JA, Jones CE, Junker U, Hofstetter H, Wolf RM, Seuwen K (2003) Proton-sensing G-protein-coupled receptors. Nature 425:93-98.

Luecke H, Lanyi JK (2003) Structural clues to the mechanism of ion pumping in bacteriorhodopsin. Adv Protein Chem 63:111-130.

McBain CJ, Mayer ML (1994) N-methyl-D-aspartic acid receptor structure and function. Physiol Rev 74:723-760.

Mott DD, Doherty JJ, Zhang S, Washburn MS, Fendley MJ, Lyuboslavsky P, Traynelis SF, Dingledine R (1998) Phenylethanolamines inhibit NMDA receptors by enhancing proton inhibition. Nat Neurosci 1:659-667.

Mott DD, Washburn MS, Zhang S, Dingledine RJ (2003) Subunitdependent modulation of kainate receptors by extracellular protons and polyamines. J Neurosci 23:1179-1188.

Nedergaard M, Kraig RP, Tanabe J, Pulsinelli WA (1991) Dynamics of interstitial and intracellular $\mathrm{pH}$ in evolving brain infarct. Am J Physiol 260:R581-R588.

Paoletti P, Perin-Dureau F, Fayyazuddin A, Le Goff A, Callebaut I, Neyton J
(2000) Molecular organization of a zinc binding $\mathrm{n}$-terminal modulatory domain in a NMDA receptor subunit. Neuron 28:911-925.

Pomes R, Roux B (2002) Molecular mechanism of $\mathrm{H}^{+}$conduction in the single-file water chain of the gramicidin channel. Biophys J 82:2304-2316.

Pomes R, Yu CH (2003) Relay and blockage of protons in water chains. Front Biosci 8:d1288-d1297.

Popescu G, Auerbach A (2003) Modal gating of NMDA receptors and the shape of their synaptic response. Nat Neurosci 6:476-483.

Premkumar LS, Qin F, Auerbach A (1997) Subconductance states of a mutant NMDA receptor channel kinetics, calcium, and voltage dependence. J Gen Physiol 109:181-189.

Prod'hom B, Pietrobon D, Hess P (1987) Direct measurement of proton transfer rates to a group controlling the dihydropyridine-sensitive $\mathrm{Ca}^{2+}$ channel. Nature 329:243-246.

Root MJ, MacKinnon R (1994) Two identical noninteracting sites in an ion channel revealed by proton transfer. Science 265:1852-1856.

Ruppersberg JP (2000) Intracellular regulation of inward rectifier $\mathrm{K}^{+}$channels. Pflügers Arch 441:1-11.

Sagnella DE, Laasonen K, Klein ML (1996) Ab initio molecular dynamics study of proton transfer in a polyglycine analog of the ion channel gramicidin A. Biophys J 71:1172-1178.

Sansom MS (1998) Models and simulations of ion channels and related membrane proteins. Curr Opin Struct Biol 8:237-244.

Schulte U, Hahn H, Konrad M, Jeck N, Derst C, Wild K, Weidemann S, Ruppersberg JP, Fakler B, Ludwig J (1999) pH gating of ROMK (K(ir)1.1) channels: control by an Arg-Lys-Arg triad disrupted in antenatal Bartter syndrome. Proc Natl Acad Sci USA 96:15298-15303.

Schulte U, Weidemann S, Ludwig J, Ruppersberg J, Fakler B (2001) $\mathrm{K}^{+}$dependent gating of $\mathrm{K}(\mathrm{ir}) 1.1$ channels is linked to $\mathrm{pH}$ gating through a conformational change in the pore. J Physiol (Lond) 534:49-58.

Siesjo BK (1985) Acid-base homeostasis in the brain: physiology, chemistry, and neurochemical pathology. Prog Brain Res 63:121-154.

Sobolevsky AI, Beck C, Wollmuth LP (2002) Molecular rearrangements of the extracellular vestibule in NMDAR channels during gating. Neuron 33:75-85.

Sobolevsky AI, Yelshansky MV, Wollmuth LP (2003) Different gating mechanisms in glutamate receptor and $\mathrm{K}^{+}$channels. J Neurosci 23:7559-7568.

Tang CM, Dichter M, Morad M (1990) Modulation of the N-methyl-Daspartate channel by extracellular $\mathrm{H}^{+}$. Proc Natl Acad Sci USA 87:6445-6449.

Traynelis SF, Cull-Candy SG (1990) Proton inhibition of N-methyl-Daspartate receptors in cerebellar neurons. Nature 345:347-350.

Traynelis SF, Cull-Candy SG (1991) Pharmacological properties and $\mathrm{H}^{+}$ sensitivity of excitatory amino acid receptor channels in rat cerebellar granule neurones. J Physiol (Lond) 433:727-763.

Traynelis SF, Hartley M, Heinemann SF (1995) Control of proton sensitivity of the NMDA receptor by RNA splicing and polyamines. Science 268:873-876.

Traynelis SF, Burgess MF, Zheng F, Lyuboslavsky P, Powers JL (1998) Control of voltage-independent zinc inhibition of NMDA receptors by the NR1 subunit. J Neurosci 18:6163-6175.

Vyklicky Jr L, Vlachova V, Krusek J (1990) The effect of external pH changes on responses to excitatory amino acids in mouse hippocampal neurones. J Physiol (Lond) 430:497-517.

Wood MW, VanDongen HM, VanDongen AM (1995) Structural conservation of ion conduction pathways in $\mathrm{K}$ channels and glutamate receptors. Proc Natl Acad Sci USA 92:4882-4886.

Wu X, Christensen BN (1996) Proton inhibition of the NMDA-gated channel in isolated catfish cone horizontal cells. Vision Res 36:1521-1528.

Yoneda Y, Enomoto R, Ogita K (1994) Supporting evidence for negative modulation by protons of an ion channel associated with the $\mathrm{N}$-methylD-aspartate receptor complex in rat brain using ligand binding techniques. Brain Res 636:298-307. 